\title{
A Randomized Controlled Phase Ilb Trial of Antigen- Antibody Immunogenic Complex Therapeutic Vaccine in Chronic Hepatitis B Patients
}

\author{
Dao-Zhen Xu' ${ }^{1}$, Kai Zhao ${ }^{2}$, Li-Min Guo ${ }^{1}$, Xin-Yue Chen ${ }^{3}$, Hui-Fen Wang ${ }^{4}$, Ji-Ming Zhang ${ }^{5}$, Qin Xie ${ }^{6}$, Hong \\ Ren ${ }^{7}$, Wen-Xiang Wang ${ }^{8}$, Lan-Juan $\mathrm{Li}^{9}{ }^{9}$, Min Xu ${ }^{10}$, Pei Liu ${ }^{11}$, Jun-Qi Niu ${ }^{12}$, Xue-Fan Bai ${ }^{13}$, Xin-Liang Shen ${ }^{2}$, \\ Zheng-Hong Yuan ${ }^{14}$, Xuan-Yi Wang ${ }^{14,15}$, Yu-Mei Wen ${ }^{14 *}$ \\ 1 Ditan Hospital, Beijing, China, 2 Beijing Institute of Vaccine and Biological Products, Beijing, China, 3 You-An Hospital, Capital Medical University, Beijing, China, 4302 \\ Military Hospital, Beijing, China, 5 Hua-Shan Hospital, Fudan University, Shanghai, China, $\mathbf{6}$ Rui-Jin Hospital, Shanghai Jiaotong University, Shanghai, China, 7 Second \\ affiliated hospital, Chongqing Medical University, Chongqing, China, 8 First affiliated hospital, Chongqing Medical University, Chongqing, China, 9 First affiliated hospital, \\ Zhejiang University, Hanzhou, Zhejiang Province, China, 10 Guangzhou Eighth Hospital, Guangzhou, Guangdong Province, China, 11 Second Hospital Affiliated to China \\ Medical University, Shenyang, Liaoning Province, China, 12 First affiliated hospital, Jilin University, Changchun, Jilin Province, China, 13 Tangdu Hospital, Fourth Military \\ Medical University, Xi'an, Shanxi Province, China, 14 Key Laboratory Medical Molecular Virology, Shanghai Medical College, Fudan University, Shanghai, China, 15 Institute \\ of Biological Sciences, Fudan University, Shanghai, China
}

\begin{abstract}
Background: The safety of the immune complexes composed of yeast-derived hepatitis B surface antigen (HBsAg) and antibodies (abbreviated as YIC) among healthy adults and chronic hepatitis B patients has been proved in phase I and phase Ila trial. A larger number of patients for study of dosage and efficacy are therefore needed.

Methods and Principal Findings: Two hundred forty two HBeAg-positive chronic hepatitis B patients were immunized with six injections of either $30 \mu \mathrm{g}$ YIC, $60 \mu \mathrm{g}$ of YIC or alum adjuvant as placebo at four-week intervals under code. HBV markers and HBV DNA were monitored during immunization and 24 weeks after the completion of immunization. The primary endpoint was defined as loss of HBeAg, or presence of anti-HBe antibody or suppression of HBV DNA, while the secondary endpoint was both $\mathrm{HBeAg}$ seroconversion and suppression of HBV DNA. Statistical significance was not reached in primary endpoints four weeks after the end of treatment among three groups, however, at the end of follow-up, HBeAg seroconversion rate was $21.8 \%(17 / 78)$ and $9 \%(7 / 78)$ in the $60 \mu \mathrm{g}$ YIC and placebo groups respectively $(p=0.03)$, with $95 \%$ confidence intervals at $1.5 \%$ to $24.1 \%$. Using generalized estimating equations (GEEs) model, a significant difference of group effects was found between $60 \mu \mathrm{g}$ YIC and the placebo groups in terms of the primary endpoint. Eleven serious adverse events occurred, which were $5.1 \%, 3.6 \%$, and 5.0\% in the placebo, $30 \mu \mathrm{g}$ YIC and $60 \mu \mathrm{g}$ YIC groups respectively $(\mathrm{p}>0.05)$

Conclusions: Though statistical differences in the preset primary and secondary endpoints among the three groups were not reached, a late and promising HBeAg seroconversion effect was shown in the $60 \mu \mathrm{g} \mathrm{YIC} \mathrm{immunized} \mathrm{regimen.} \mathrm{By}$ increasing the number of patients and injections, the therapeutic efficacy of YIC in chronic hepatitis B patients will be further evaluated.
\end{abstract}

\section{Trial Registration: ChiCTR.org ChiCTR-TRC-00000022}

Citation: Xu D-Z, Zhao K, Guo L-M, Chen X-Y, Wang H-F, et al. (2008) A Randomized Controlled Phase Ilb Trial of Antigen-Antibody Immunogenic Complex Therapeutic Vaccine in Chronic Hepatitis B Patients. PLoS ONE 3(7): e2565. doi:10.1371/journal.pone.0002565

Editor: Torbjorn Ramqvist, Karolinska Institutet, Sweden

Received November 23, 2007; Accepted May 28, 2008; Published July 2, 2008

Copyright: (C) $2008 \mathrm{Xu}$ et al. This is an open-access article distributed under the terms of the Creative Commons Attribution License, which permits unrestricted use, distribution, and reproduction in any medium, provided the original author and source are credited.

Funding: This work was supported by grants from State high Technology Grant from China (2002AA2Z3303 and 2004AA2Z3970), Shanghai Municipal Government Commission of Science and Technology (Grant number G 1999054105).

Competing Interests: The authors have declared that no competing interests exist.

* E-mail: ymwen@shmu.edu.cn

\section{Introduction}

According to the World Health Organization, there are 350 million people worldwide, who are chronically infected with HBV. Prolonged chronic hepatitis B results in the development of liver cirrhosis, liver failure, or hepatocellular carcinoma[1]. The pathogenesis of $\mathrm{HBV}$ in chronically infected patients has been well- studied and reviewed. Lack of effective immune responses, notably, defective cell-mediated immune responses (CD4, CD8 and NK cells, cytolytic responses) against HBV, defective dendritic cell (DC) functions and imbalance of cytokine production have been identified as the major mechanisms for virus persistence and initiation of chronic liver disease $[2,3,4,5,6]$. Effective host immune responses are crucial to terminate viral persistence. To overcome the defects in immune responses, various therapeutic measures have been designed to boost effective host immune 
responses [7,8,9,10,11,12,13]. Immune complexes (IC) composed of antigen and antibodies have long been used to induce potent antibody responses against microbial proteins and other proteins in animals [14]. Whether IC can be used for therapeutic treatment of viral hepatitis $\mathrm{B}$ patients has been questioned because circulating immune complexes (CIC) have been found in some chronic hepatitis B patients [15]. We hypothesized that the crucial difference between CIC and the immune complexes composed of yeast-derived hepatitis B surface antigen ( $\mathrm{HBsAg}$ ) and antibodies (abbreviated as YIC) used in this study is that, in CIC, the antiHBs antibodies from the patient are of low affinity, which cannot efficiently bind to $\mathrm{HBsAg}$ and clear the protein from the host. In contrast, the anti-HBs used to produce YIC are generated from healthy adults who were immunized multiple times with yeastderived recombinant HBsAg. Therefore, these are high affinity antibodies that can combine efficiently with HBsAg [16]. When YIC is administered via intramuscular injections, it served as an immunogen to the host, and antigen presenting cells in the immune tolerant host would be forced to uptake the $\mathrm{HBsAg}$ complexed to its antibodies via the $\mathrm{Fc}_{\mathrm{C}}$ receptors on antigen presenting cells, and thereby leading to modified antigen processing and presentation in the complex. This hypothesis has been confirmed by our previous experimental studies in animal models and in vitro experiments on human dendritic cells $[17,18]$. A recent preliminary study in a small number of chronic hepatitis B patients showed that the therapeutic effect of YIC correlated with both cytolytic and noncytolytic responses [19].Though antiviral drugs are highly effective in inhibiting HBV replication, emergence of drug resistance and rebound of virus replication after withdrawal of drugs are major disadvantages for treatment of persistent viral infections [20,21]. Conversely, vaccine therapy is an inexpensive and promising approach for the treatment of persistent viral infections [22,23].

To study the in vivo immunotherapeutic effects of YIC in chronic hepatitis B patients, a double-blind, randomized, placebocontrolled clinical study was conducted, and results are presented.

\section{Methods}

The protocol for this trial and supporting CONSORT checklist are available as supporting information; see Checklist S1 and Protocol S1.

\section{Immune complexes and placebo}

Both the immune complexes and placebo used in this study were manufactured by Beijing Institute of Vaccine and Biological Products, and the Chinese Good manufacture practice (GMP) regulation was followed. Each dose of $1 \mathrm{~mL}$ immune complexes (YIC) consisted of either 30 or $60 \mu \mathrm{g}$ of $\mathrm{HBsAg}$ complexed to human anti-HBs immunoglobulin (HBIG) at an appropriate ratio (described in US patent 6,221,664 B1 and European patent 913157), using alum as the adjuvant, which was a mixture of $\mathrm{KAl}\left(\mathrm{SO}_{4}\right)_{2}$ and $\mathrm{NaOH}$. The placebo contained $0.1 \%$ alum identical to that being used in YIC as the adjuvant.

\section{Study design}

This double-blind, randomized, and placebo-controlled study was conducted at 12 evaluation centers for the treatment of HBV, which were certificated by the State Food and Drug Administration (SFDA), China. Prior to initiating the clinical trial, the protocol of this study was submitted, registered, licensed and approved by the SFDA, China (license number 2002L0038). The trial was registered at WHO International Clinical Trials Registry Platform. Final approval from the ethics committee at Ditan hospital after ethical evaluating at each participating center was completed in February 2005, and enrollment of patients was initialed in March, 2005. Prior to enrollment, each patient signed a written consent for participating in this trial.

The study was designed in a three-arm fashion. Eligible patients were assigned to receive $30 \mu \mathrm{g}$ YIC, $60 \mu \mathrm{g}$ YIC or placebo in blocks of 6 (two for the $30 \mu \mathrm{g}$ YIC vaccine, two for the $60 \mu \mathrm{g}$ YIC vaccine, and two for the placebo group) through computer generated random numbers on the label of study agent vial in terms of recruiting sequence. An independent biostatistician was in charge of the processing of randomization using SAS program (SAS Institute Inc., Cary, NC, USA). All participants were immunized with six intramuscular injections at 4- week intervals, and followed for 24 weeks after the termination of immunization. Serum samples were collected from each patient at baseline, 12th, 24th, 36th and 44th week after initial injection, and separated into two vials. One vial of serum was used for routine biochemical and hematological tests, such as ALT, AST, and was conducted immediately at each evaluation center. Another vial serum was storied at $-70^{\circ} \mathrm{C}$ at each center and shipped to the reference lab at Beijing Ditan Hospital at the end of study for assays of HBV markers and virus load of all samples from all centers. The study was designed by a chief clinical investigator in Ditan Hospital, and was monitored by TigerMed, China, an independent Contract Research Organization. The principles of good clinical practice and clinical trial-related guidelines issued by SFDA were implemented throughout the study.

\section{Patients}

Patients with chronic hepatitis B, aged 18-65 years old, who were $\mathrm{HBsAg}$ and $\mathrm{HBeAg}$ positive for at least 6 months and who were anti-HBe negative with an HBV viral load >100,000 copies/ $\mathrm{mL}$ and a serum ALT of two to ten times the upper limit of normal value within four weeks before randomization were recruited at each evaluation center. Exclusion criteria were co-infection with hepatitis A, C, D and E virus, or HIV; taking antiviral, hepatotoxic or immunosuppressive drugs or products within the preceding 6 months; other causes of liver disease; serious medical or psychiatric illness; hepatic cirrhosis or AFP > $100 \mathrm{ng} / \mathrm{mL}$; abnormal serum creatinine, thrombocyte count, hemaglobin or serum total bilirubin; and pregnancy.

\section{Assays}

Routine biochemical and hematological tests, such as ALT, AST, were carried out at each evaluation center using automated techniques available at each center.

At the end of study, all frozen serum samples from all enrolled patients under code were transferred from all evaluation centers to the reference lab at Beijing Ditan Hospital for assays of $\mathrm{HBeAg}$, anti-HBe and serum HBV DNA levels. Samples at all time points were thawed and assayed using the same lot of reagents. Sequential samples from one patient were tested on the same day. Abbott EIA AxSYM (Abbott, Abbott Park, IL, USA) was employed for $\mathrm{HBsAg}, \mathrm{HBeAg}$, and anti-HBe. According to protocols provided by the manufacturer, positive and negative cutoffs were calculated, with the positive and negative controls as required by the diagnostic kits. Serum HBV DNA was quantified by fluorescent PCR assay using the ABI equipment, and reagents were from Piji, Shenzhen Co, China, with a detection limit of 500 copies/mL.

\section{Endpoints}

The virologic response was assessed four weeks after the end of treatment (week 24) and 24 weeks after the end of treatment (week 
44, the end of follow-up). HBeAg seroconversion was defined by the loss of $\mathrm{HBeAg}$ and the presence of anti-HBe antibody. Suppression of HBV DNA was defined as the $>2 \log 10$ decrease of viral load. The primary endpoint was defined as loss of $\mathrm{HBeAg}$, or presence of anti-HBe antibody or suppression of HBV DNA. The secondary endpoint was designated as both $\mathrm{HBeAg}$ seroconversion and suppression of HBV DNA.

\section{Safety}

All participants were observed for local reactions and systemic symptoms through diary card and follow-up interview. The causality of adverse events was determined by the clinical investigators, and the criteria for severe adverse events were: blood total bilirubin (TB) $>3 \times 17.2 \mu \mathrm{mol} / \mathrm{L}$ ), prolonged prothrombin time $(\mathrm{PTA})<40 \%$ ), and ALT levels elevated 10 times higher than that of the baseline. The severity of adverse events was classified as mild (easily tolerated; causing minimal discomfort; not interfering normal everyday activities), moderate (Sufficiently discomforting to interfere with normal everyday activities) and severe (Prevents normal everyday activities). Safety analysis was performed on all patients who underwent randomization and received at least one dose of study agent.

\section{Data management and statistical analysis}

The sample size was calculated to ensure an adequate evaluation of the primary endpoint. Based on the literatures and the results of phase IIa trial, a sample size of 78 patients per arm could detect a difference of primary response rate between $60 \mu \mathrm{g}$ group, $30 \mu \mathrm{g}$ group and placebo group (response rate in $60 \mu \mathrm{g}$ YIC group vs placebo group, $35 \%$ vs $3 \%$; and response rate in $30 \mu \mathrm{g}$ YIC group vs placebo group, $20 \%$ vs $3 \%$ ) with a statistical power of $80 \%$ at the 0.05 level of significance, allowing for a dropout rate of $20 \%$.

All data were double entered into custom-made data entry programs. The data management programs included range and consistency checks. An SAS program (SAS Institute Inc., Cary, NC, USA) was applied for statistical analysis. Analysis was conducted on all eligible patients according to the intent-to-treat principle. HBV DNA was logarithmically transformed for analysis. For binary data, the Chi square test, or Fisher's exact test when data were sparse, were employed. For dichotomous outcomes, ANOVA was used.

Repeated measures analysis was performed using a generalized estimating equations (GEEs) method to adjust the dependence among repeated observations made on the same patient while testing the group and time effects [24]. In the model, we included the time effect as a class variable which used three indicator variables. The indicator variable was defined by treating Week 44 as a baseline time. Similarly, the group effect was defined by using two indicator variables, where the placebo group served as baseline group. Since there were only four repeated measurements (week 12, 24, 36, and 44), we applied the unstructured (UN) working covariance matrix which provided robust estimation of covariance to the structure. Since the ALT and HBV DNA are crucial indicators for baseline assessment, adjustments were made for group, baseline ALT and HBV DNA. A p-value $<0.05$ (twotailed) was considered statistically significant.

\section{Results}

\section{Baseline characteristics of enrolled patients}

Three hundred and fifty four hepatitis B patients were evaluated for the inclusion criteria. Of these, 242 patients were eligible and assigned randomly to placebo, $30 \mu \mathrm{g}$ YIC and $60 \mu \mathrm{g}$ YIC groups in a three-month period. Five patients were found ineligible during the batch assay at the end of treatment (week 24) at the central laboratory, and therefore were excluded from the intent-to-treat analysis. Of 237 patients included in the analysis , 8 receiving placebo, 5 receiving $30 \mathrm{ug}$ YIC, and 10 receiving $60 \mathrm{ug}$ YIC either did not complete the treatment, did not complete the follow-up or violated the protocol (Figure 1). No significant difference was found in baseline characteristics among three groups (Table 1).

\section{Kinetics of responses in patients}

As shown in Table 2, a delayed response to YIC was observed between 24 weeks and the end of follow-up. For intent-to-treat analysis, at the end of follow-up, 31, 35 and 28 patients achieved the primary endpoint, and 6, 7 and 14 patients reached the secondary endpoint in the placebo, $30 \mu \mathrm{g}$ YIC and $60 \mu \mathrm{g}$ YIC groups, respectively. The response rate for secondary endpoint in the $60 \mu \mathrm{g}$ YIC group was comparatively higher than that of the other groups, though statistical significance had not been reached. However, at the end of follow-up, a significant difference on $\mathrm{HBeAg}$ seroconversion was found between $60 \mu \mathrm{g}$ YIC and placebo groups $(p=0.03,2-$ tailed). The $95 \%$ confidence interval for this difference was $1.5 \%$ to $24.1 \%$. In contrast, a statistical significance had not been reached between $30 \mu \mathrm{g}$ YIC and placebo groups.

Furthermore, when applying the GEEs method to estimate the group and time effects, a significant difference of group effects was found between the $60 \mu \mathrm{g}$ group and the placebo group in terms of the primary endpoint, and response rate calculated by both primary and secondary endpoints changed significantly over the time in the placebo, $30 \mu \mathrm{g}$ and $60 \mu \mathrm{g}$ YIC groups $(\mathrm{p}<0.05)$ (Table 3).

When the baseline serum HBV DNA and levels of HBeAg from all secondary responders at the end of follow-up in the three groups were analyzed, among the 14 patients immunized with $60 \mu \mathrm{g}$ YIC, five had HBV DNA $\geq 10^{7}$ copies $/ \mathrm{ml}$, eight had HBV DNA $\geq 10^{6}$ and $<10^{7}$ copies $/ \mathrm{ml}$, only one had HBV DNA $10^{5}$ copies $/ \mathrm{ml}$. In contrast, of the 6 patients immunized with alum, five patients had HBV DNA $10^{5}$ copies $/ \mathrm{ml}$, one had HBV DNA $\geq 10^{6}$ and $<10^{7}$ copies/ml, none of them had HBV DNA $\geq 10^{7}$ copies $/ \mathrm{ml}$.

\section{Reversion of $\mathrm{HBeAg}$ and rebound of HBV DNA}

The incidence of rebound in virus replication and reversion to serum HBeAg at the end of follow-up were compared among the three groups. For those responders who reached the secondary endpoint, none of the patients from either the $60 \mu \mathrm{g}$ YIC group or placebo group showed a rebound in virus load nor in reversion to serum HBeAg. In contrast, four responders in the $30 \mu \mathrm{g}$ YIC group showed a virus load rebound to the baseline level and $\mathrm{HBeAg}$ reverted to positive. Interestingly, rebound of viral load and reversion to serum $\mathrm{HBeAg}$ were all from responders who only reached the primary endpoint at the end of immunization, while none occurred in those who reached the secondary endpoint, suggesting that patients who achieved the secondary response at the endpoint of treatment were unlikely to develop reversion.

\section{Adverse events and severe adverse events}

Overall, the most common systematic symptoms were similar for the three groups. However, more local reactions were found in the $60 \mu \mathrm{g}$ YIC and $30 \mu \mathrm{g}$ YIC groups. In the placebo group, the most common reaction was pain at the injection site, followed by malaise and fatigue; in the $30 \mu \mathrm{g}$ and $60 \mu \mathrm{g}$ YIC group, the most common adverse events were pain at the injection site, pruritus and swelling (Table 4). During study period, eleven patients experienced elevated ALT levels over ten times the normal level, accompanied by high levels of serum bilirubin and thus were hospitalized.

The occurrence of serious adverse events calculated according to the intent-to-treat principle was $5.1 \%(4 / 79), 3.6 \%(3 / 83)$, and 


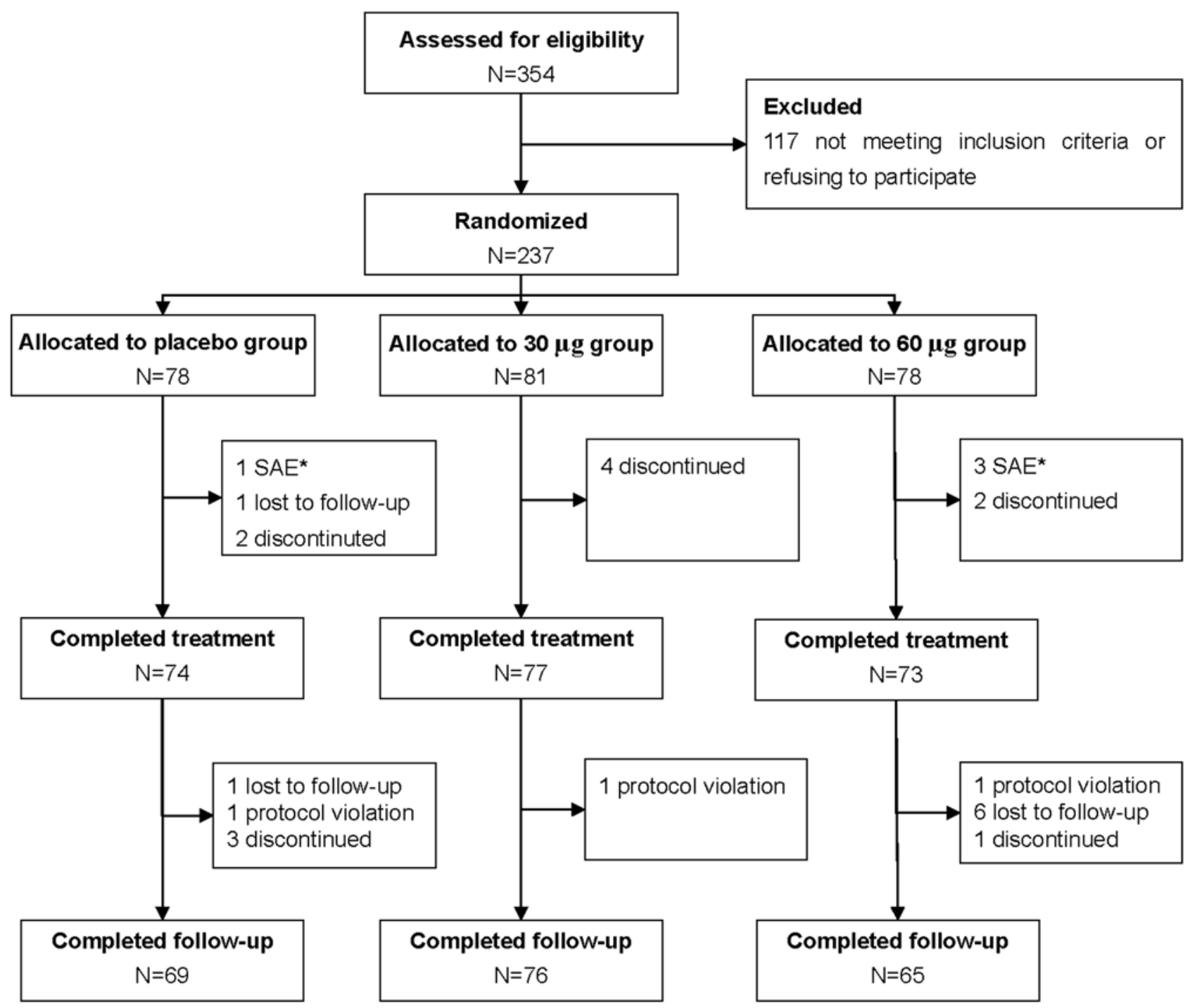

Figure 1. Summary of participants. Footnote: The numbers of SAE patients are those who discontinued treatment, while other SAE patients are not included in this figure.

doi:10.1371/journal.pone.0002565.g001

$5.0 \%(4 / 80)$ in the placebo, $30 \mu \mathrm{g}$ YIC and $60 \mu \mathrm{g}$ YIC groups respectively $(p>0.05)$. Ten of these were males, while one was female. The age of patients with SAE varied between 21 and 4 years of age. Four occurred after the first injection (2 in placebo group, 2 in $60 \mu \mathrm{g}$ YIC group), two occurred after the second injection ( 1 in placebo group, 1 in $30 \mu \mathrm{g}$ YIC group), one occurred after 5 injections (in $30 \mu \mathrm{g}$ YIC group), and the other four appeared after 6 injections ( 1 in placebo group, 1 in $30 \mu \mathrm{g} \mathrm{YIC}$

Table 1. Characteristics of participants.

\begin{tabular}{llll}
\hline Characteristics & Placebo group (N=78) & $\mathbf{3 0} \mu \mathbf{g}$ YIC group (N=81) & $\mathbf{6 0} \mu \mathbf{g}$ YIC group (N= 78) \\
\hline Age (yr; SD) & $27.9 \pm 7.6$ & $28.6 \pm 8.6$ & $28.8 \pm 8.0$ \\
Female sex (no.; \%) & $19(24.4)$ & $22(27.2)$ & $17(21.8)$ \\
Weight (kg; SD) & $61.7 \pm 11.1$ & $62.3 \pm 10.0$ & $63.7 \pm 9.3$ \\
Course of illness, hepatitis B (yr; SD) & $6.3 \pm 5.2$ & $6.0 \pm 5.8$ & $6.1 \pm 5.4$ \\
Family history, hepatitis B (no.;\%) & $46(59.0)$ & $46(56.8)$ & $46(59.0)$ \\
Alanine aminotransferase (IU/liter; SD) & $169.6 \pm 80.0$ & $162.5 \pm 74.7$ & $171.8 \pm 93.4$ \\
HBV DNA (log copies/mL; SD) & $7.1 \pm 0.9$ & $7.1 \pm 0.9$ & $7.2 \pm 0.8$ \\
\hline
\end{tabular}

SD: Standard deviation.

doi:10.1371/journal.pone.0002565.t001 
Table 2. Virologic response at the end of treatment and the end of follow-up.

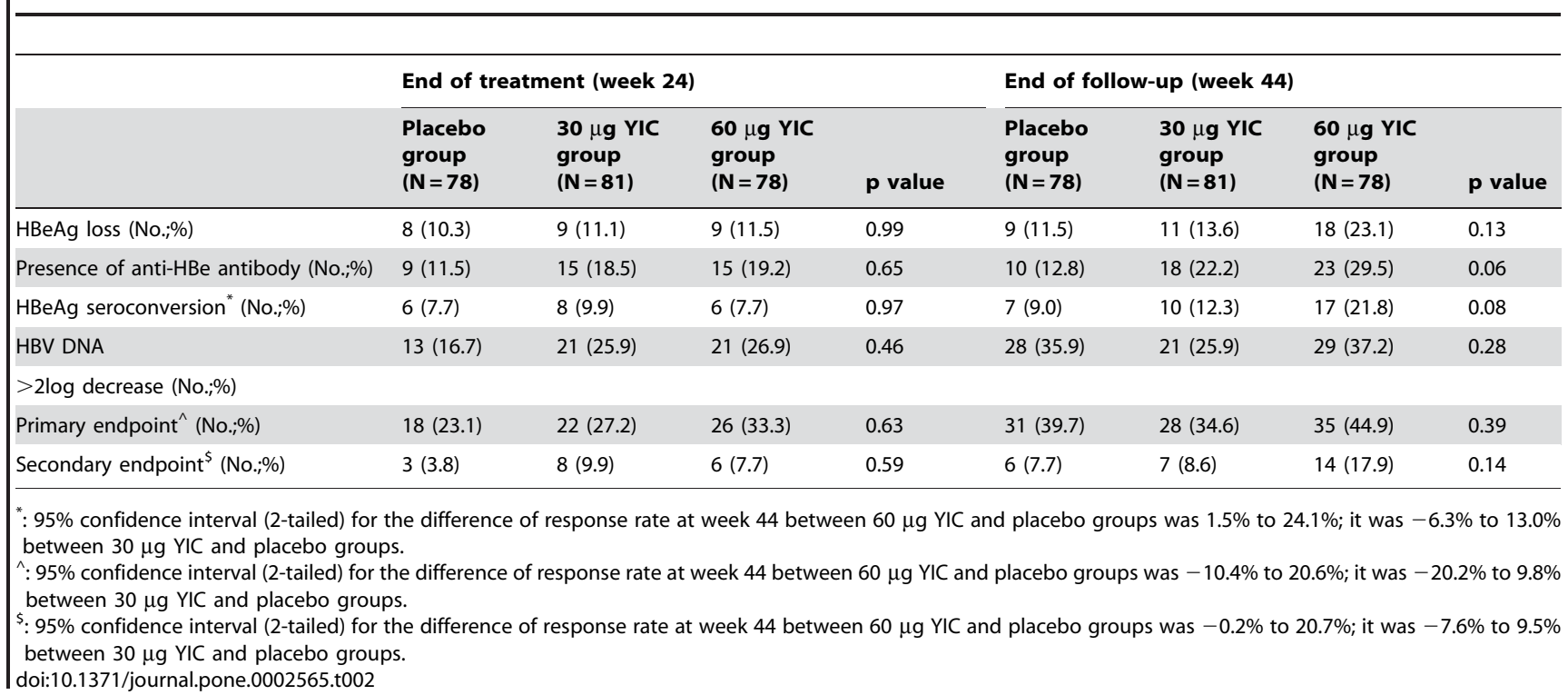

group and 2 in $60 \mu \mathrm{g}$ YIC group). All 11 patients were hospitalized and recovered after treatment without immunomodulating drugs (one patient used antiviral treatment). No deaths were observed during the study period.

\section{Discussion}

In this study, statistical significant differences in the preset primary and secondary endpoints among the three groups of patients were not reached at the end of treatment or of follow up. Nevertheless, patients immunized with intramuscular injections of $60 \mu \mathrm{g}$ YIC showed the highest rates of $\mathrm{HBeAg}$ loss (23.1\%), $\mathrm{HBeAg}$ seroconversion $(21.8 \%)$ and suppression of HBV DNA $(37.2 \%)$ at the end of follow-up (44 weeks). When one of the primary endpoints ( $\mathrm{HBeAg})$ seroconversion, was compared between $60 \mu \mathrm{g}$ YIC and placebo groups at the end of follow-up, statistical significance was observed $(\mathrm{p}=0.03)$. Interestingly, these rates in $60 \mu \mathrm{g}$ YIC group at 44 weeks markedly surpassed those achieved at 24 weeks, namely, HBeAg loss $(23.1 \%$ vs $11.5 \%)$, HBeAg seroconversion $(21.8 \%$ vs7.7\%) and suppression of HBV DNA (37.2\% vs26.9\%) (Table 2). An important difference between YIC as an active immunotherapeutic vaccine versus passive immunotherapies such as using interferon, thymosin et al for treatment, is that, active immunotherapeutic approach functions through inducing immune responses in the patients; while in passive immunotherapeutic approaches, the immunological modulating products are repeatedly introduced into patients, and thus continuously providing the patients with the necessary immunological modulating products. The former approach needs only few injections at relatively long intervals, while the latter needs repeated injections of products to immunomodulate host immune responses. Therefore, it is not surprising, a late and sustained response versus YIC immunization was observed in a subpopulation of patients.

Though the response rates with respect to the secondary endpoints in the $60 \mu \mathrm{g}$ YIC group were comparatively higher than that of the other groups, due to the unexpected rates of $\mathrm{HBeAg}$ seroconversion and suppression of serum HBV DNA in the alum immunized group, statistical significance was not reached. Nevertheless, after adjusting the dependence among repeated observations made on the same patient, a significant change of response rate over the study period was detected in the placebo, $30 \mu \mathrm{g}$ and $60 \mu \mathrm{g}$ YIC groups, with respect to either primary or secondary endpoints $(\mathrm{p}<0.05)$ (Table 3$)$.

It was intriguing that only alum immunization resulted in a decrease of HBV viral load and seroconversion of $\mathrm{HBeAg}$ in some patients. As shown in the analysis of patients who reached secondary response at the end of follow-up, the baseline serum HBV DNA in patients who responded to alum alone immunization predominantly were those who had lower levels of serum HBV DNA $\left(10^{5}\right.$ copies/ $\mathrm{mL}$ ). Whether this phenomenon was due to spontaneous seroconversion in patients needs to be considered. Ideally, to include a group of patients without injections as additional control in the study

Table 3. Repeated measures analysis for time and group effects controlling by baseline ALT and HBV DNA.

\begin{tabular}{|c|c|c|c|c|}
\hline \multirow[t]{2}{*}{ Group } & \multicolumn{2}{|l|}{ Primary endpoint } & \multicolumn{2}{|l|}{ Secondary endpoint } \\
\hline & OR (95\% confidence interval) & p value & OR (95\% confidence interval) & p value \\
\hline $30 \mu \mathrm{g}$ YIC group vs placebo group & $0.9(0.5-1.4)$ & 0.52 & $1.3(0.5-3.6)$ & 0.60 \\
\hline $60 \mu \mathrm{g}$ YIC group vs placebo group & $1.7(1.0-2.7)$ & 0.04 & $2.2(0.9-5.4)$ & 0.09 \\
\hline Week 12 vs Week 44 & $0.3(0.2-0.5)$ & $<0.0001$ & $0.3(0.2-0.6)$ & 0.0006 \\
\hline Week 24 vs Week 44 & $0.5(0.4-0.7)$ & $<0.0001$ & $0.6(0.4-0.9)$ & 0.01 \\
\hline Week 36 vs Week 44 & $0.7(0.6-1.0)$ & 0.04 & $0.6(0.4-1.0)$ & 0.04 \\
\hline
\end{tabular}


Table 4. Occurrence of most common adverse events during treatment and follow-up.

\begin{tabular}{|c|c|c|c|c|}
\hline \multirow[t]{2}{*}{ Adverse events } & \multicolumn{3}{|c|}{ No. of patients (\%) } & \multirow[t]{2}{*}{ p value } \\
\hline & $\begin{array}{l}\text { Placebo } \\
\text { group } \\
(\mathrm{N}=79)\end{array}$ & $\begin{array}{l}30 \mu \mathbf{g} \text { YIC } \\
\text { group } \\
(\mathbf{N}=\mathbf{8 3})\end{array}$ & $\begin{array}{l}60 \mu \mathrm{g} Y I C \\
\text { group } \\
(\mathrm{N}=80)\end{array}$ & \\
\hline \multicolumn{5}{|c|}{ Local adverse reaction } \\
\hline Erythema & $6(7.6)$ & $15(18.1)$ & $15(18.8)$ & 0.08 \\
\hline Swelling & $9(11.4)$ & 19 (22.9) & $25(31.3)$ & 0.009 \\
\hline Pain & $32(40.5)$ & $42(50.6)$ & $45(56.3)$ & 0.13 \\
\hline Pruritus & $12(15.2)$ & $22(26.5)$ & $34(42.5)$ & 0.0006 \\
\hline \multicolumn{5}{|l|}{ Systematic symptom } \\
\hline Fever & 11 (13.9) & $8(9.6)$ & $11(13.8)$ & 0.63 \\
\hline Malaise & $16(20.3)$ & $12(14.5)$ & $12(15.0)$ & 0.57 \\
\hline Headache & $8(10.1)$ & $9(10.8)$ & $17(21.3)$ & 0.09 \\
\hline Dizziness & $11(13.9)$ & $11(13.3)$ & $18(22.5)$ & 0.24 \\
\hline Fatigue & $14(17.7)$ & $19(22.9)$ & $19(23.8)$ & 0.62 \\
\hline Vomiting & $5(6.3)$ & $5(6.0)$ & $4(5.0)$ & 0.94 \\
\hline Nausea & $8(10.1)$ & $9(10.8)$ & $14(17.5)$ & 0.35 \\
\hline Abdominal pain & $6(7.6)$ & $6(7.2)$ & $8(10.0)$ & 0.84 \\
\hline Diarrhoea & $6(7.6)$ & $6(7.2)$ & $4(5.0)$ & 0.81 \\
\hline
\end{tabular}

may well clarify this issue. However, due to ethical concern, as well as double blinding principle, such study design has not been approved. Using the data from a previous study by Yuen et al as a reference, the one year $\mathrm{HBeAg}$ sero-conversion rate in patients treated with IFN- $\alpha$ and untreated patient was $21.1 \%$ and $2.2 \%$ [25]. In another clinical trial of lamivudine treatment, at the end of one year, the $\mathrm{HBeAg}$ sero-conversion rate was $8.3 \%$ in the treated group [26]. These studies suggested that the $21.8 \%$ of $\mathrm{HBeAg}$ seroconversion rate in Chinese patients observed in this study most likely was not due to spontaneous sero-conversion. Besides, by pair-wise comparison, significance of $\mathrm{HBeAg}$ seroconversion rate was only found between the $60 \mu \mathrm{g}$ YIC and the placebo groups, other than between the $30 \mu \mathrm{g}$ YIC and the placebo groups, which further supported the previous finding was not due to spontaneous seroconversion. As for the 10 patients in the $60 \mu \mathrm{g}$ YIC immunized group who only reached primary responses at the end of treatment, attained secondary responses during follow-up, could be due to a late response to YIC immunization, however, spontaneous HBeAg seroconversion should be excluded. Recently, it was reported that immune complex-loaded dendritic cells were superior to soluble immune complexes as an anti-tumor vaccine in animals [27], Furthermore, antigen-antibody immune complexes were reported to

\section{References}

1. Lee WM (1997) Hepatitis B virus infection. N Engl J Med 337: 1733-1745.

2. Rehermann B, Nascimbeni M (2005) Immunology of hepatitis B virus and hepatitis C virus infection. Nat Rev Immunol 5: 215-229.

3. Bertoletti A, Ferrari C (2003) Kinetics of the immune response during HBV and HCV infection. Hepatology 38: 4-13.

4. Chisari FV, Ferrari C (1995) Hepatitis B virus immunopathogenesis. Annu Rev Immunol 13: 29-60.

5. Ganem D, Prince AM (2004) Hepatitis B virus infection-natural history and clinical consequences. N Engl J Med 350: 1118-1129.

6. Webster GJ, Reignat S, Brown D, Ogg GS, Jones L, et al. (2004) Longitudinal analysis of CD8+ T cells specific for structural and nonstructural hepatitis B virus proteins in patients with chronic hepatitis B: implications for immunotherapy. J Virol 78: 5707-5719. empower dendritic cells to efficiently prime specific CD8+ CTL responses in vivo [28]. These studies strengthened our confidence in using immune complexes as a therapeutic vaccine for persistent infections. Compared to passive immunotherapy, we consider active immunization by YIC is a simple-to-use, less expensive and promising therapeutic vaccine in a subpopulation of chronic hepatitis B patients.

Regarding the effect of alum, it was reported that alum alone can promote $\mathrm{B}$ cell activation in mice, which could bypass the priming effect needed for B cell responses [29]. Whether alum also can induce $\mathrm{T}$ cell responses is still under discussion [30]. One may speculate that immunization with alum alone activated the $\mathrm{B}$ cells in some chronic hepatitis B patients and when these B cells came across the circulating $\mathrm{HBsAg}$ in these patients, a low level of immune responses to $\mathrm{HBsAg}$ might be triggered and eventually could lead to decrease in virus load, and /or sero-conversion of HBeAg.

Patients who developed severe adverse events were distributed almost equally in the three groups. It was surprising that three patients immunized with only alum developed severe adverse events, and two of them even developed severe adverse events after only one injection. The severe adverse events in these two patients were verified by highly elevated ALT levels attaining $937 \mathrm{U} / \mathrm{L}$ and $818 \mathrm{U} / \mathrm{L}$ with TB $111.6 \mu \mathrm{mol} / \mathrm{L}$ and $54.8 \mu \mathrm{mol} / \mathrm{L}$ respectively. In the forthcoming phase III clinical trial, not only the therapeutic efficacy of YIC should be evaluated, but also severe adverse events will be closely monitored and investigated.

\section{Supporting Information}

Protocol S1 Trial Protocol.

Found at: doi:10.1371/journal.pone.0002565.s001 (0.49 MB DOC)

Ghecklist S1 CONSORT Checklist.

Found at: doi:10.1371/journal.pone.0002565.s002 (0.06 MB DOC)

\section{Acknowledgments}

We are grateful to Prof. Blaine Hollinger (Baylor College of Medicine, TX, USA) for his invaluable advice and comments. We thank Dr. Li-Feng Xu (Beijing Institute of Vaccine and Biological Products), Prof Bing-Hua Su, Drs. Zhao-Hui Wei, Xiao-Li Shi (Tigred Inc, China) for their contributions in this study.

In particularly, we are grateful to Prof. Tae-Sung Park (Department of Statistic, Seoul National University, Seoul, Korea). He had reviewed statistical analysis, especially the analysis using GEE model.

\section{Author Contributions}

Conceived and designed the experiments: YW DX KZ LG XS ZY. Performed the experiments: DX LG XC HW JZ QX HR WW LL MX PL JN XB. Analyzed the data: YW ZY XW. Contributed reagents/materials/ analysis tools: XS. Wrote the paper: YW ZY XW.

7. Sprengers D, Janssen HL (2005) Immunomodulatory therapy for chronic hepatitis B virus infection. Fundam Clin Pharmacol 19: 17-26.

8. Pol S, Driss F, Michel ML, Nalpas B, Berthelot P, et al. (1994) Specific vaccine therapy in chronic hepatitis B infection. Lancet 344: 342.

9. Mancini M, Hadchouel M, Davis HL, Whalen RG, Tiollais P, et al. (1996) DNA-mediated immunization in a transgenic mouse model of the hepatitis $\mathrm{B}$ surface antigen chronic carrier state. Proc Natl Acad Sci USA 93: 12496-12501.

10. Pancholi P, Lee DH, Liu Q Tackney C, Taylor P, et al. (2001) DNA prime/ canarypox boost-based immunotherapy of chronic hepatitis $\mathrm{B}$ virus infection in a chimpanzee. Hepatology 33: 448-454.

11. Akbar SMF, Furukawa S, Onji M, Murata Y, Niya T, et al. (2004) Safety and efficacy of hepatitis B surface antigen-pulsed dendritic cells in human volunteers. Hepatol Res 29: 136-141. 
12. Mancini-Bourgine M, Fontaine H, Bréchot C, S SP, Michel ML (2006) Immunogenicity of a hepatitis B DNA vaccine administered to chronic HBV carriers. Vaccine 24: 4482-4489.

13. Heathcote J, McHutchison J, Lee S, Tong M, Benner K, et al. (1999) A pilot study of the CY-1899 T-cell vaccine in subjects chronically infected with hepatitis B virus. Hepatology 30: 531-536.

14. Randall RE, Young DF, Southern JA (1988) Immunization with solid matrixantibody-antigen complexes containing surface or internal virus structural proteins protects mice from infection with the paramyxovirus, simian virus 5 . J Gen Virol 69: 2517-2526.

15. Michalak T (1978) Immune complexes of hepatitis B surface antigen in the pathogenesis of periarteritis nodosa. A study of seven necropsy cases. Am J Pathol 90: 619-632.

16. Brown SE, Howard CR, Zuckerman AJ, Steward MW (1984) Affinity of antibody responses in man to hepatitis $\mathrm{B}$ vaccine determined with synthetic peptides. Lancet 2: 184-187.

17. Zheng BJ, Ng MH, He LF, Yao X, Chan KW, et al. (2001) Therapeutic efficacy of hepatitis B surface antigen-antibodies-recombinant DNA composite in HBsAg transgenic mice. Vaccine 19: 4219-4225.

18. Zheng BJ, Zhou J, Qu D, Siu KL, Lam TW, et al. (2004) Selective functional deficit in dendritic cell- $\mathrm{T}$ cell interaction is a crucial mechanism in chronic hepatitis B virus infection. J Viral Hepat 11: 217-224.

19. Yao X, Zheng B, Zhou J, Xu DZ, Zhao K, et al. (2007) Therapeutic effect of hepatitis B surface antigen-antibody complex is associated with cytolytic and non-cytolytic immune responses in hepatitis B patients. Vaccine 25: 1771-1779.

20. Aloman C, Wands JR (2003) Resistance of HBV to adefovir dipivoxil: a case for combination antiviral therapy? Hepatology 38: 1584-1587.
21. Liaw YF, Leung NW, Chang TT, Guan R, Tai DI, et al. (2000) Effects of extended lamivudine therapy in Asian patients with chronic hepatitis B. Asia Hepatitis Lamivudine Study Group. Gastroenterology 119: 172-180.

22. Cohen J (1994) Vaccines get a new twist. Science 264: 503-505

23. Pol S, Michel ML (2006) Therapeutic vaccination in chronic hepatitis B virus carriers. Expert Rev Vaccines 5: 707-716.

24. Zeger SL, Liang KY (1986) Longitudinal data analysis for discrete and continuous outcomes. Biometrics 42: 121-130.

25. Yuen MF, Hui GK, Cheng CC, Wu CH, Lai YP, et al. (2001) Long-term followup of interferon alfa treatment in Chinese patients with chronic hepatitis $\mathrm{B}$ infection: The effect on hepatitis $\mathrm{B}$ e antigen seroconversion and the development of cirrhosis-related complications. Hepatology 34: 139-145.

26. Yao GB, Cui ZY, Wang BE, Yao JL, Zeng MD (2004) A 3-year clinical trial of lamivudine in treatment of patients with chronic hepatitis B. Hepatobiliary Pancreat Dis Int 3: 188-193.

27. Schuurhuis DH, van-Montfoort N, Ioan-Facsinay A, Jiawan R, Camps M, et al. (2006) Immune complex-loaded dendritic cells are superior to soluble immune complexes as antitumor vaccine. J Immunol 176: 4573-4580.

28. Schuurhuis DH, Ioan-Facsinay A, Nagelkerken B, van-Schip JJ, Sedlik C, et al. (2002) Antigen-antibody immune complexes empower dendritic cells to efficiently prime specific CD8+ CTL responses in vivo. J Immunol 168: 2240-2246.

29. Jordan MB, Mills DM, Kappler J, Marrack P, Cambier JC (2004) Promotion of $\mathrm{B}$ cell immune responses via an alum-induced myeloid cell population. Science 304: 1808-1810.

30. Brewer JM (2006) (How) do aluminium adjuvants work? Immunol Lett 102: 10-15. 